Scientific Journal of Silesian University of Technology. Series Transport Zeszyty Naukowe Politechniki Śląskiej. Seria Transport

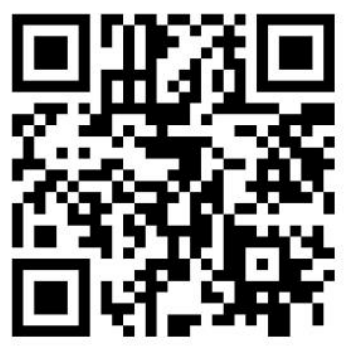

Volume 111

2021

p-ISSN: 0209-3324

e-ISSN: 2450-1549

DOI: https://doi.org/10.20858/sjsutst.2021.111.3

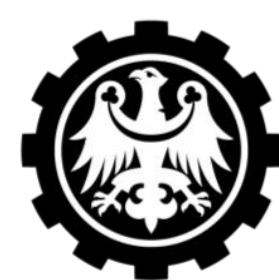

Silesian

University of Technology

Journal homepage: http://sjsutst.polsl.pl

Article citation information:

Fabiś, P., Flekiewicz, M. Optimalisation of the SI engine timing advance fueled by LPG. Scientific Journal of Silesian University of Technology. Series Transport. 2021, 111, 33-41. ISSN: 0209-3324. DOI: https://doi.org/10.20858/sjsutst.2021.111.3.

\author{
Pawel FABIŚ ${ }^{1}$, Marek FLEKIEWICZ ${ }^{2}$
}

\title{
OPTIMALISATION OF THE SI ENGINE TIMING ADVANCE FUELED BY LPG
}

Summary. This study is an attempt to determine the control parameters of the control system for gaseous fuels currently used for driving vehicles. It presents the selected dynamic parameters of the car obtained when fueling the engine with petroleum-based LPG. This paper attempts to determine the optimal timing advance of the gas-air mixture and the efficiency of its processing in the drive system of the tested vehicle driven by a four-cylinder engine with a $1.6 \mathrm{dm}$. More so, this article includes an analysis of the influence of the optimised power charts of the engine on the dynamics of the motion of a motor vehicle running on gaseous fuel. To present changes in the dynamics of movement, indicators and parameters determining changes in the dynamics of vehicle movement, such as dynamic coefficient, acceleration and flexibility were used. Through this analysis, it is possible to verify the optimised power and torque waveform and determine whether the vehicle dynamics improved.

Keywords: LPG, power charts, timing advance

\footnotetext{
${ }^{1}$ Faculty of Transport and Aviation Engineering, The Silesian University of Technology, Krasińskiego 8 Street, 40-019 Katowice, Poland. Email: pawel.fabis @ polsl.pl. ORCID: https://orcid.org/0000-0001-6087-6467

2 Auto Gaz Śląsk, Brygadzistów 82a Street, 40-807 Katowice, Poland. Email:mflekiewicz@autogaz.com.pl. ORICID: https://orcid.org/0000-0002-0251-246X
} 


\section{INTRODUCTION}

The achievement of low emissions in exhaust gases from SI engines currently determines the development trends of motor vehicles. These include both the introduction of new technical and technological solutions in fuel injection systems, improvement of the combustion process, exhaust gas cleaning systems, and the use of alternative fuels. The advantage of using alternative fuels is, among other things, the fact that the combustion engine driving the vehicle does not require major modifications, and the existing infrastructure ensures the smooth supply of these fuels. In addition, the currently applicable dual-fuel alternative gasoline or LPG or CNG systems are solutions that increase vehicle autonomy, considering its beneficial environmental aspects, it also ensures the economics of operation due to the advantageous price ratio compared to gasoline $[9,10]$. Despite the critical assessments of environment benefits resulting from the use of alternative gaseous fuels, which appear in some scientific studies, most vehicle manufacturers include them in the adopted development strategies of the product being manufactured [1,2]. This is also because currently available technologies enable the production of these fuels from biomass, thus, qualifies them for renewable fuels. Current LPG and CNG systems ensure relatively fast adaptation of the vehicle to fuel with these fuels, and the results of their tests, carried out following the requirements of UN / ECE Regulation 115, confirm the reduction of $\mathrm{CO}_{2}$ emissions and controlled exhaust components compared to the emission obtained for gasoline.

The scope of tests carried out following the requirements of Regulation 115 does not specify dynamic indicators of a motor vehicle, and in most publications, it presents only the maximum power achieved by the engine or on the wheels of a motor vehicle. Hence, in this article, tests were carried out aimed at comparing the influence of the ignition advance angle on selected indicators characterising the vehicle performance. The basis for calculations were the external characteristics of the Opel Astra 1.6 engine, which was powered by LPG. The engine and the fuel dose control system did not introduce any changes, modifications were introduced in the management of the ignition advance angle. Obtained results of the calculations explain the effect of changes in the ignition advance angle on changes in the dynamics of the tested vehicle.

\section{TEST OBJECT CHARACTERISTICS}

The SI engine of the Opel Astra 1.6 was used in the tests. Its basic technical parameters together with the characteristics of the car are shown in Table 1 . The engine was powered by LPG fuel, using independent power supply systems, providing the engine with a mixture of liquefied gases with a pressure not exceeding $0.5 \mathrm{MPa}$. The system provided a multi-point injection of gaseous fuel, whereby the gas condensed after evaporation was injected at a pressure of $10.0 \mathrm{kPa}$. The simplified block diagram of the system is shown in Figure 1. In contrast, Figure 2 explains how to control the dose of gaseous fuel.

Based engine data characterised researched car shown in Table 1.

The performance of the car was determined by analysing its dynamic characteristics, expressing the dependence of power developed on the wheels from the speed of the car, which was obtained using a Bosch FLA 203 chassis dynamometer. A simplified diagram of the position is shown in Figure 3. Changes in the ignition advance angle were conducted using a programmable computer allowing for changing the settings of the data at each engine work point or within a specified range. Further, the test stand was equipped with transducers and sensors that ensure the identification of the engine's operating status. The basic control and 
measurement systems ensuring continuous recording of the engine operation state were, inter alia, devices enabling measurement of:

- pressure in the engine cylinders,

- angle of rotation of the crankshaft with the determination of the piston GMP,

- power developed on the wheels of the tested car,

- negative pressure prevailing in the intake manifold,

- temperature of the intake air and exhaust gases.

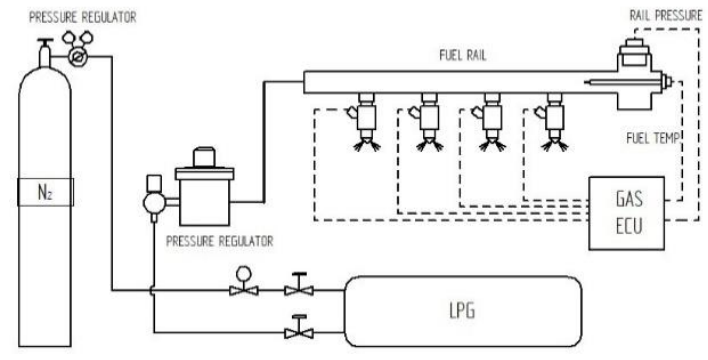

Fig. 1. Scheme of operating system [9]

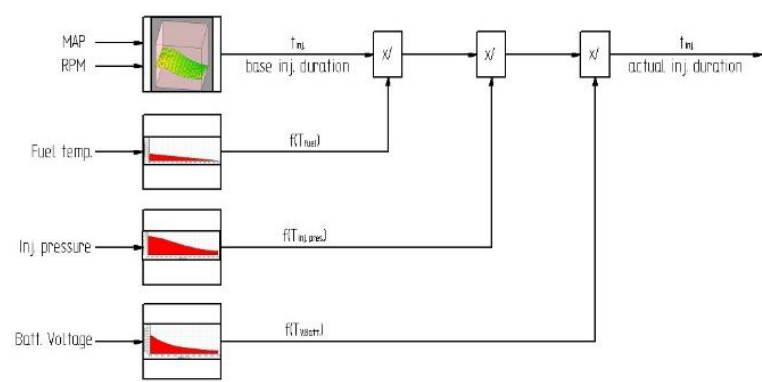

Fig. 2. Scheme of engine control system [9]

Tab. 1

Based parameters of the car engine

\begin{tabular}{|l|c|}
\hline Number of cylinders & $4 \mathrm{R}$ \\
\hline Maximum power and RPM & $55 \mathrm{~kW} / 52001 / \mathrm{min}$ \\
\hline Maximum torque and RPM & $128 \mathrm{Nm} / 28001 / \mathrm{min}$ \\
\hline Capacity & $1598 \mathrm{~cm}^{3}$ \\
\hline Diameter & $79.0 \mathrm{~mm}$ \\
\hline Stroke & $81.5 \mathrm{~mm}$ \\
\hline Compresion ratio & 9.6 \\
\hline
\end{tabular}

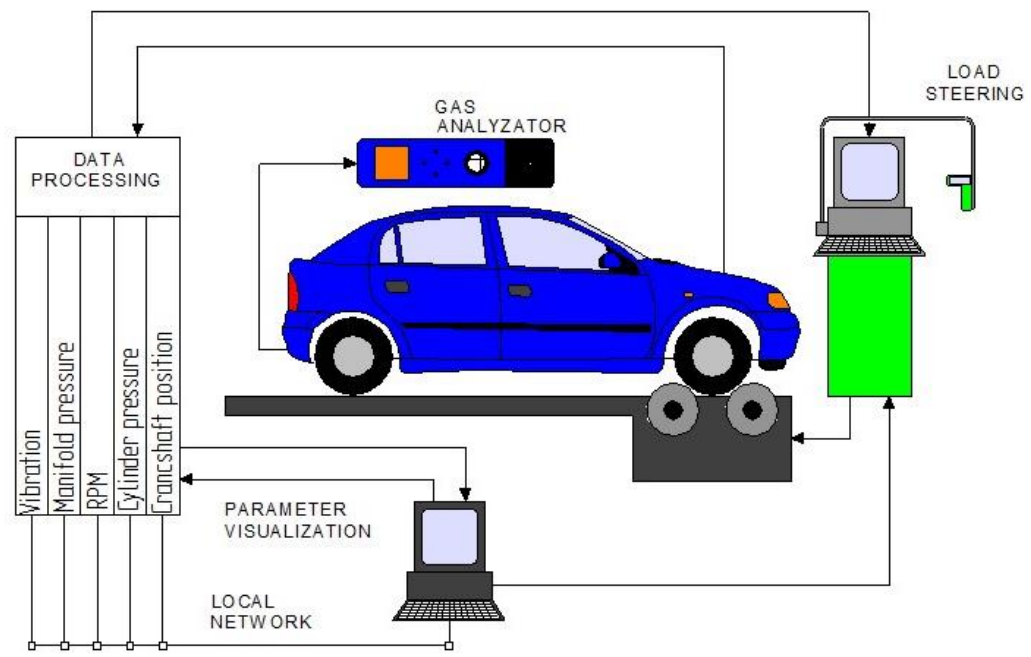

Fig. 3. Scheme of testing stand [9] 
The pressure inside the cylinder was measured using a 6121 piezoelectric pressure sensor and KISTLER type 5011 charge amplifier. The position of the crankshaft and its rotational speed were determined using the KISTLER type 2613B crankshaft position marker. This transducer is an integral part of the gasoline fuel dose management system, injected into the intake manifold of the tested car's engine.

The mass flow of gaseous fuel flowing into the engine power system was measured using a precision tensometric weight. All measured parameters were recorded and visualised using the NI PCI-6143 data acquisition card and a proprietary program developed in the environment LabView 7.1.

\section{RESULTS AN DISCUSSION}

\subsection{Power and torque results}

The results of power and torque measurements developed by the car engine, fueled by LPG at various ignition timing angles, are presented in Table 2, and the course of changes in power and torque depending on the engine speed is shown in Figure 4.

Tab. 2

Power and torque received during dynamometers test

\begin{tabular}{|c|c|c|c|c|c|}
\hline L.p. & Fuel and CA change & $\begin{array}{c}\text { Power } \\
{[\mathrm{kW}]}\end{array}$ & $\begin{array}{c}\mathrm{n}_{\mathrm{N}} \\
{\left[\mathrm{min}^{-1}\right]}\end{array}$ & $\begin{array}{c}\text { Torque } \\
{[\mathrm{Nm}]}\end{array}$ & $\begin{array}{c}\mathrm{n}_{\mathrm{M}} \\
{\left[\mathrm{min}^{-1}\right]}\end{array}$ \\
\hline 1 & LPG 0CA & 55,02 & 5051 & 125,19 & 3337 \\
\hline 2 & LPG +3CA & 54,55 & 4812 & 125,96 & 3288 \\
\hline 3 & LPG +6CA & 54,34 & 5190 & 126,08 & 2889 \\
\hline 4 & LPG -2CA & 55,07 & 5210 & 125,06 & 3367 \\
\hline 5 & LPG opt & 56,27 & 5091 & 132,55 & 2600 \\
\hline
\end{tabular}

The obtained results indicate a clear change in the engine power and torque depending on the ignition advance angle in the gas mixture feeding the engine. By increasing the lead in the ignition angle, the maximum power and torque are reduced. If the value of the ignition advance angle is reduced, a clear increase in the maximum power value is observed. The situation changes dramatically when the ignition advance angle is optimised and values changing the torque and power curve in specific speed ranges are introduced. In the 1000 - 2500 min- 1 speed range, an angle of +6 st has been entered, in the range of 2,500 - 4,500 min- 1 an angle of +3 degrees has been introduced, while in the range above 4500 min-1 an angle of -2st has been introduced. When using such an optimised ignition angle, a distinct change in the external motor characteristics is obtained. 


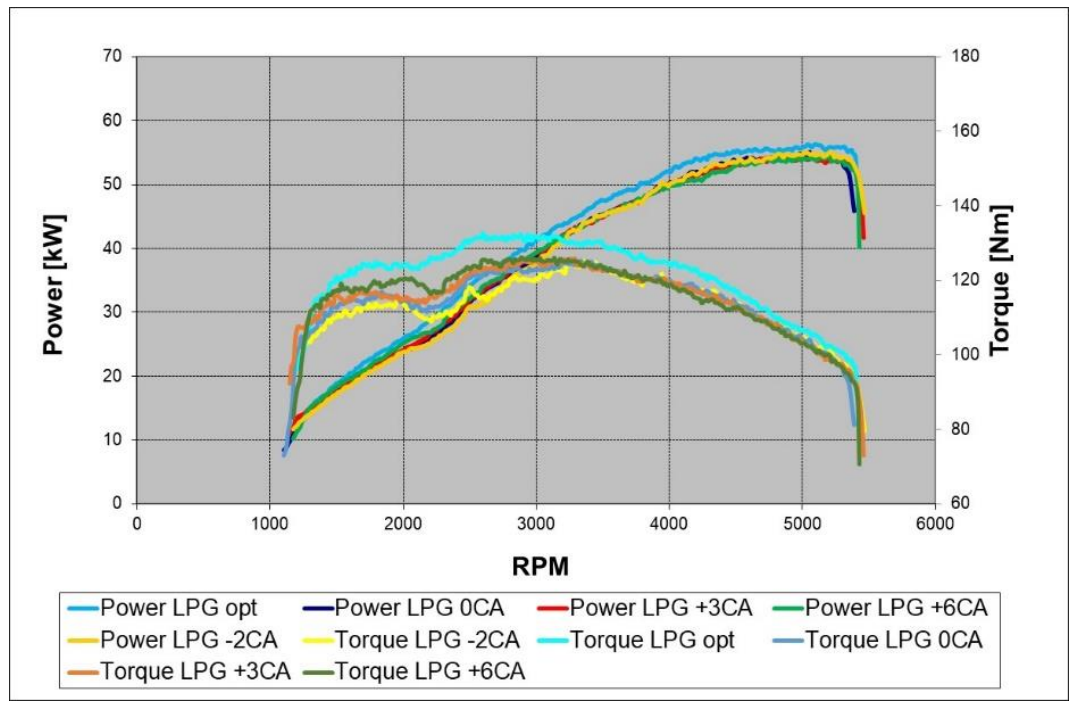

Fig. 4. Performance characteristics of engine powered by LPG with different crank angle set up

\subsection{Method for fast determination of a dynamic factor and vehicle acceleration}

The dynamic properties of the car are compared using technical indicators expressing unit power, force or mass values. However, the dynamic indicator is usually used in the lowest and highest gears. It is the most universal indicator defining the car's engine properties, for example, climbing ability, ability to accelerate and overcome road resistance. This ratio is expressed as the following relationship:

$$
D=\frac{T_{e \max } \cdot i_{o} \cdot i_{g} \cdot \eta_{m}-F_{a} \cdot r_{d}}{W \cdot r_{d}}
$$

where:

$\mathrm{T}_{\text {emax }}$ - engine max torque, $\mathrm{Nm}$,

$\mathrm{i}_{\mathrm{o}}$ - final drive ratio,

$\mathrm{i}_{\mathrm{g}}-$ gear ratio,

$\mathrm{F}_{\mathrm{a}}-$ Air resistance force, $\mathrm{N}$,

$\eta_{\mathrm{m}}-$ mechanical efficiency of the transmission drive,

$\mathrm{W}-$ Total vehicle weight, [N],

$\mathrm{r}_{\mathrm{d}}-$ dynamic radius of the wheel, $\mathrm{N}$.

Usually, its value is determined in the highest gear. Figure 5 shows the dynamic coefficient waveforms for different values of the ignition advance angle and the mileage optimised.

Acceleration of the vehicle in a particular gear $\left(a_{i}\right)$ can be calculated from the following expression:

$$
a_{i}=\frac{g}{\delta_{i}}\left(D_{i}-f\right)
$$


where:

$g$ - acceleration of $\mathrm{g}$-force,

$D_{i}-$ dynamic factor (characteristic) in a particular gear,

$f$ - rolling resistance coefficient,

$\delta_{\mathrm{i}}$ - rotating masses influence coefficient.

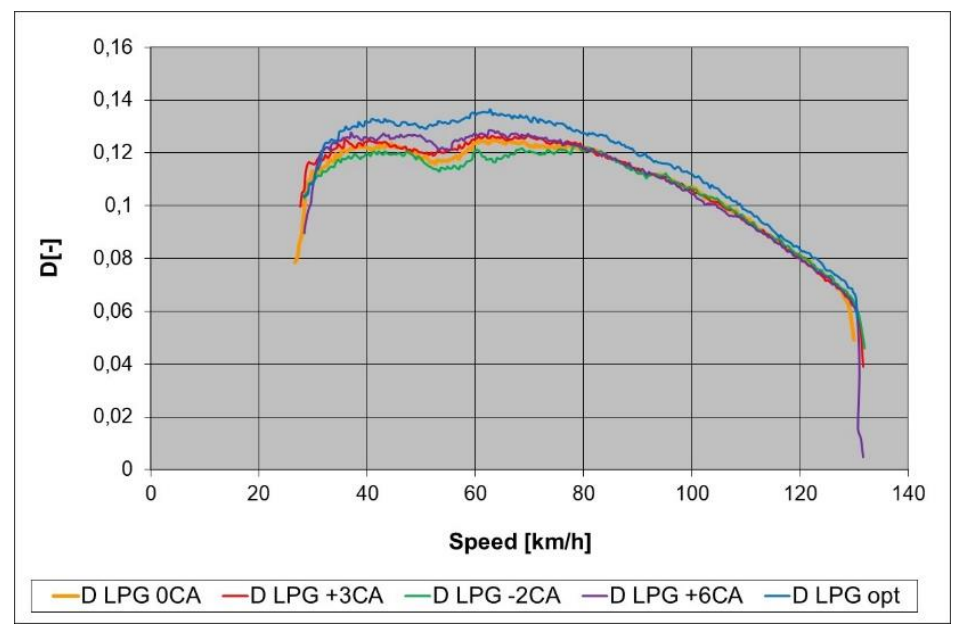

Fig. 5. Dynamic factor characteristics of engine powered by LPG with various timing advance

The analysis of the results from the above figure shows that LPG with optimalised crank angle gave higher car dynamics than the rest set angles. The difference between the fuels is clearly visible in the whole range of car speed. It is caused by the different crank angle set up for different rpm range as shown above.

Figure 6 shows the engine flexibility as a supplement describing the change in the car dynamics.

Described engine flexibility at some part of range is the same value as a dynamic factor as seen in Figure 7. The exception is the higher value of flexibility optimalisation LPG fuel with corrected spark timing.

\section{CONCLUSIONS}

Researches on the use of vehicle feed LPG fuel allowed describing how the kind of engine parameter includes car dynamic. Due to the description of done dyno test which given power and torque engine allows calculation of dynamic factor, accelerations and flexibility. Certified that the crank angle timing influences the maximum power and torque value. An appropriately set crank angle timing is given the torque and power increase. Set one timing angle for whole rpm range improves the torque and power value only for the chosen range. This is the reason for the optimalisation of the crank angle timing for the whole rpm range as it improves its given power and torque at all range. Proposed value of timing angle optimalising and improve the course of power and torque. For the proposed timing angle value $\left(+6^{\circ} \mathrm{CA},+3^{\circ} \mathrm{CA}\right.$ and $\left.-2^{\circ} \mathrm{CA}\right)$, power increased over $1 \mathrm{~kW}$ and torque over $7 \mathrm{Nm}$. 
a)

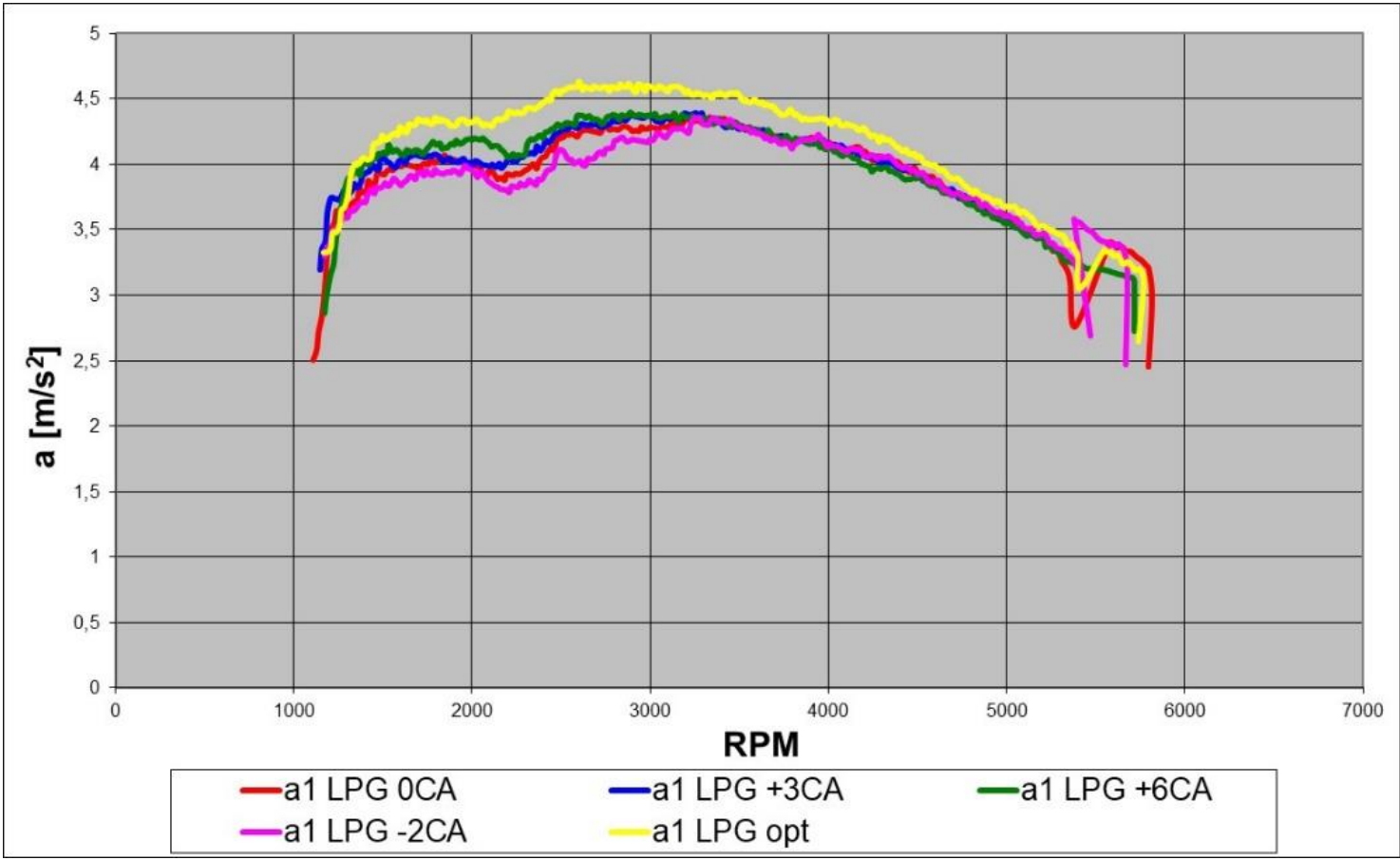

b)

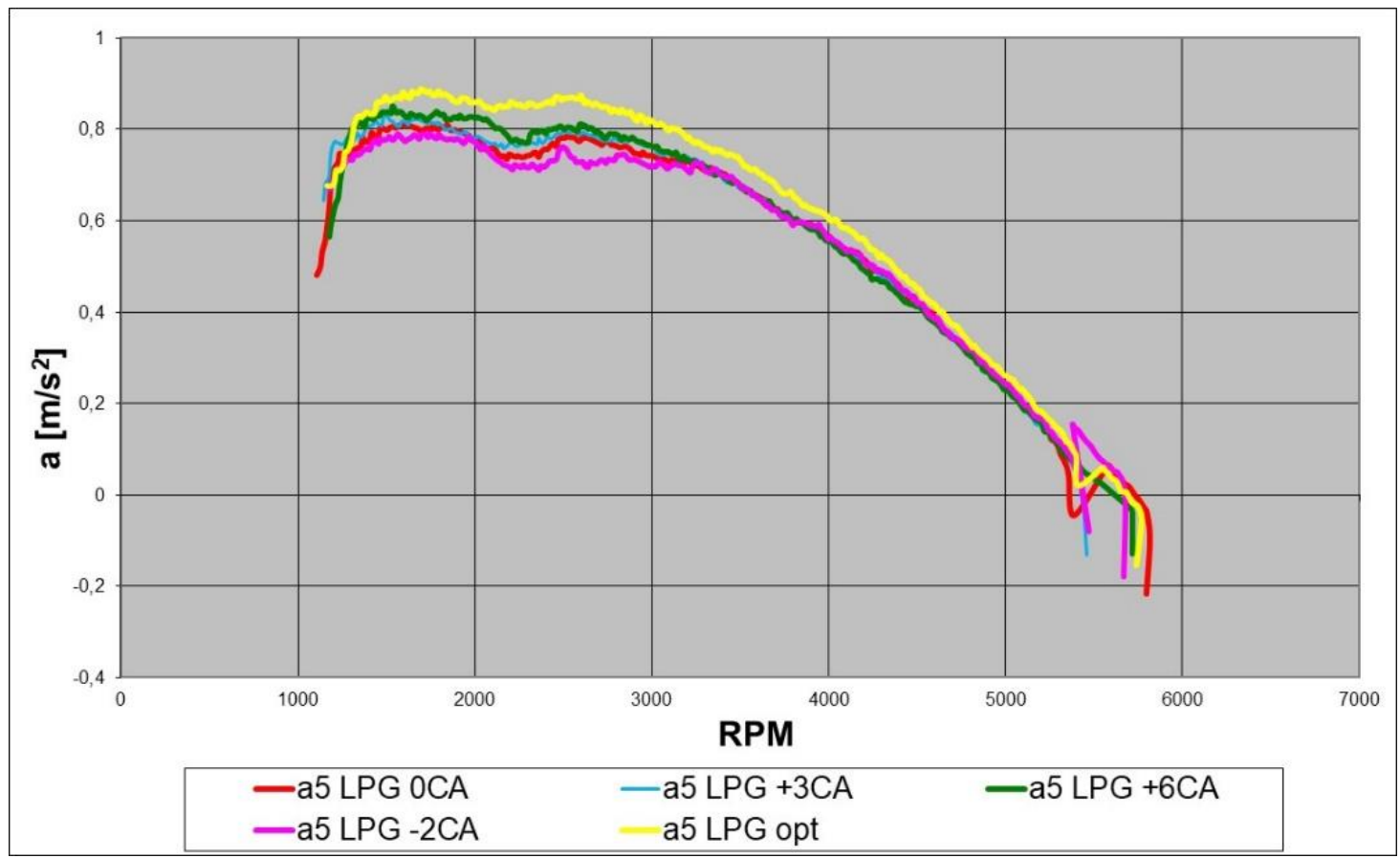

Fig. 6. Acceleration characteristics of engine powered by LPG with various timing advance, a) lowest gear, b) highest gear 


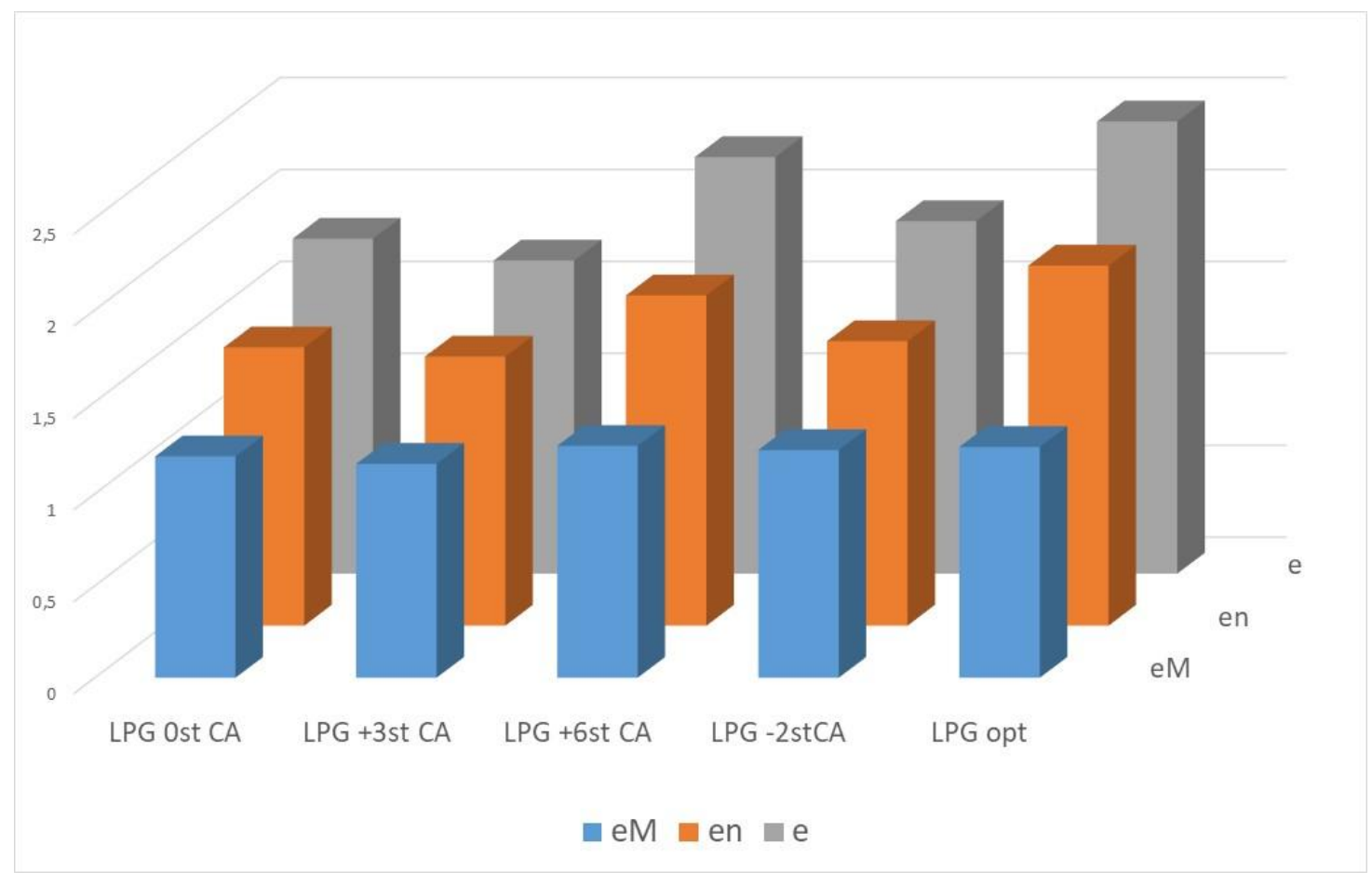

Fig. 7. Flexibility of engine powered by LPG fuels for different crank angle set up

\section{References}

1. Merkisz J., S. Radzimirski. 2006. „Does the propane-buthane gas is an ecological fuel?” Internal Combustion Engines 2(125).

2. Toyota's Strategy for Environmental Technologies. Available at: http://www.toyotaglobal.com/innovation/environmental_technology/strategy_environmental_tech.html.

3. PZPM Raport. 2013.

4. Van Mierlo J., G. Vereecken, G. Maggetto, V. Farrel, S. Meyer, W. Hecq. 2003. „Comparizon of the Environmental Damage Caused by Vehicles with Different Alternative Fuels and Drivetrains in a Brusells Context". J. Automotive Eng. Proc. IMechE Part D 217(D7): 583-594.

5. Campbell M., Ł.P. Wyszyński, R. Stone. 2004. „Combustion of LPG in a Spark-Ignition Engine". SAE Paper 2004-01-0974.

6. Fabiś P. 2005 „Measuring the indicated pressure and engine block vibration - conception of the test stand". XXXII National Symphosium of the Machine Diagnostic. Węgierska Górka, Poland.

7. Heywood J.B. 1998. Internal combustion engines fundamentals. McGraw-Hill. New York.

8. Rogers D.R. 2010. Engine Combustion: Pressure Measurement and Analysis. SAE International.

9. Usman M., N. Hayat. 2020. „Lubrication, emission and performance analyses of LPG and petrol in a motorbike engine: a comparative study". Journal of the Chinese Institute of Engineers 43(1): 47-57. Available at: https://doi.org/10.1080/02533839.2019.1676656. 
10. Simsek S., S. Uslu. 2020. „Investigation of the impacts of gasoline, biogas and LPG fuels on engine performance and exhaust emissions in different throttle positions on SI engine". Fuel 279: 118528. DOI: https://doi.org/10.1016/j.fuel.2020.118528.

Received 12.02.2021; accepted in revised form 27.04.2021

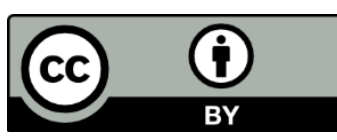

Scientific Journal of Silesian University of Technology. Series Transport is licensed under a Creative Commons Attribution 4.0 International License 